\title{
A "Comprehensive" Model for Accelerating the Building Integrated Photovoltaic (BIPV) / Wind Turbine (BIWT) Construction Projects in the Kingdom of Bahrain
}

\author{
N. W. Alnaser, R. Flanagan and W. E. Alnaser* \\ School of Construction Management, University of Reading, P.O. Box 219, Whiteknights, Reading RG6 6AW, UK; Phys- \\ ics Department, College of Science, University of Bahrain, P.O. Box 32038, Kingdom of Bahrain

\begin{abstract}
We are reporting a model for accelerating Building Integrated Photovoltaic (BIPV) or Wind Turbine (BIWT) projects in the kingdom of Bahrain which consists of two parts. The first part is dealing with establishing a simple mathematical model to calculate the Sustainable Building Index (SBI) in the kingdom of Bahrain -which was published earlier. The second part - which is the scope of this paper - is establishing a comprehensive model which consists of four arms that lead to the acceleration of BIPV and BIWT by virtue of concentrating on one - or more elements - in one arm. Each arm consists of elements in a form of policies or mechanisms that Bahrain should establish. These arms are the incentives, legislation, penalties, and strategies.
\end{abstract}

Keywords: Building integrated photovoltaic (BIPV), building integrated wind turbine (BIWT), sustainable building index, policies.

\section{INTRODUCTION}

More than a hundred publications were made to assess renewable energy resources in Bahrain but none proposed a broad strategy for using this energy for building and construction. However, major review papers on renewable energy for Gulf Cooperation Council (GCC) countries touched on policy making issues [1-7]. Few papers [8-9] were devoted to energy use and conservation in buildings in Bahrain. We conducted work [10-18] on several sustainable buildings in Bahrain emphasizing on Building Integrated Photovoltaic (BIPV) and Building Integrated Wind Turbine (BIWT). We found it necessary to establish a comprehensive model that led to the acceleration of BIPV and BIWT since buildings and construction account for nearly $70 \%$ of the energy produced in Bahrain. Therefore, we made this comprehensive model which consists of two parts. The first part is a simple mathematical model that calculates the Sustainable Building Index (SBI) in the kingdom of Bahrain [18]. This index enables players in the building and construction sector and the energy policy makers to perceive the interest of investors in the kingdom of Bahrain in conducting Building Integrated Photovoltaic (BIPV) or Building Integrated Wind Turbines (BIWT) projects, i.e. a type of sustainable or green building. It enables the calculation of the Sustainable Building Index (SBI), which ranges from 0.1 (lowest), to 1.0 (highest); the higher figure the more chance for launching BIPV or BIWT. We have found that SBI in Bahrain is 0.48 [18]. This indicates that an extensive effort must be made through policies on renewable energy, incentives to BIPV and BIWT projects, environmental awareness and promotion to clean and

\footnotetext{
*Address correspondence to this author at the Physics Department, College of Science, University of Bahrain, P.O. Box 32038, Kingdom of Bahrain; E-mail: alnaserw@gmail.com and alnaserw@batelco.com
}

sustainable energy for building and construction projects. Knowing SBI is important for us to establish a schematic comprehensive model which is expected to enhance and accelerate Building Integrated Photovoltaic (BIPV) or Wind Turbine (BIWT) projects in the kingdom of Bahrain. In fact, this mathematical model (allow calculation of calculating SBI) can be used internationally to create a "Global SBI" data base, where the Sustainable Building and Construction Initiative (SBCI), United Nations, can take this task. The second part - which is the scope of this paper - is establishing a comprehensive model which consists of four arms that lead to the acceleration of BIPV and BIWT by virtue of concentrating on one - or more elements - in one arm. Each arm consists of elements in a form of policies or mechanisms that Bahrain should establish. These arms are the incentives, legislation, penalties, and strategies.

The recent work by Taleb and Pitts [19] was devoted to study the potential to exploit the use of BIPV in GCC countries. The aim of their paper was only to assess the potential to exploit the use of a particular, but valuable, renewable energy option: BIPV in GCC countries. They conducted a large-scale survey, followed by a number of in-depth interviews, to examine the use of BIPV. Empirical research findings were presented, and then analysed in order to determine the current viability of a large-scale expansion of BIPV in the GCC region. Their research indicates that the main factors hindering expansion are high costs and the negative public perception of BIPV. They suggested proposals to assist the development of suitable policies and the wider introduction of viable BIPV in the GCC markets. They had reach to suggest policies for GCC countries similar, to a certain extent, to other work in Malaysia [20], may be due to similar technological experience and public awareness in utilizing BIPV. They [20] suggested long term strategies to reduce the cost of BIPV namely (a) Establishment of BIPV information services, awareness and capacity building programs (b) De- 
velopment of BIPV market enhancement and infrastructure development (c) Improvement of policy and financial frameworks supportive for BIPV market sustainability (d) Establishment of competitive local BIPV manufacturing industries and $\mathrm{R} \& \mathrm{D}$; the outcome of these strategies is to strengthen the industry, consumers and policy/decision makers.

In this paper we are integrating the mathematical model which we had established earlier [18] - in a comprehensive model that will lead to the acceleration and boosting of BIPV and BIWT projects in the kingdom of Bahrain. In fact no other model was ever established to lead for diffusion of BIPV and BIWT in Bahrain. The policies suggested earlier [19] are brief and general for GCC countries and can not be adopted easily in Bahrain; our model is tailor-made .

\section{THE COMPREHENSIVE MODEL}

The first part of this comprehensive model is mathematical and deals with numerically indicating the market of BIPV and BIWT in Bahrain (mature or premature), i.e. SBI of less than 0.5 means "prematurity " while more than 0.5 indicated "maturity". Through the "Barriers" and "Drivers" one can be able to improve this market. In this section we are establishing a comprehensive model that leads to the acceleration of BIPV and BIWT by virtue of concentrating on one - or more - elements in one of four arms. These arms are the incentives, penalties, legislation and strategies. For example, increasing the value of SBI - in the arm of strategies - will lead to a faster rate of BIPV projects. Also, limiting the building's electrical requirements per $\mathrm{m}^{2}$ - in the arm of legislation- and imposing taxes - in the arm of penalties - and offering easier bank loans for buying Green Building properties - in the arm of incentives - will lead to the acceleration of BIPV or BIWT in Bahrain.

\subsection{The Arm of Incentives}

Among the policies and mechanisms of our "comprehensive" model, incentives could play an important role in accelerating the BIPV and BIWT. The most important incentives are:

- Provide Free Visas for foreign workers in the construction of Green Buildings certified by an energy committee.

- Relieve import taxes on materials imported for Green Buildings.

- Adopt fast clearance procedures on materials imported for Green Building.

- State subsidy for Green Building promotion.

- Easier bank loans for buying Green Building Property.

- Easier and more relaxed finance rules for investors and contractors involved in Green Building construction.

- Government or utilities offer a financial reward for every electrical unit $(\mathrm{kWh})$ produced from solar and wind electricity in BIPV or BIWT, i.e. 30 fils per $\mathrm{kWh}$ - knowing that each $\mathrm{kWh}$ in Bahrain from conventional source costs nearly 16 fils per $\mathrm{kWh}$ for commercial application.
- Awarding a state Green Building certificate or Ecological Building certificate for BIPV or BIWT construction.

- Offer priority for BIPV or BIWT buildings at the governmental or public level at an attracting rate; government hire flats or houses in these buildings over other normal buildings.

- The government pays $10 \%$ of the solar and wind instruments and accessories for the first BIPV and BIWT commercial construction with $1 \%$ decrease for the preceded ones within a certain quota.

- Offer Pay-back. Government should give reimbursements on private residential BIPV or BIWT houses equal to $50 \%$ for the households' solar and wind equipment for the first 100 houses followed by less payback of the second 100 houses ( say 40\%) and so on. This means after the build of 500 houses no payback is offered.

- Issue bonus and prizes to those consultants and contractors that exceed the set limits and produce the most efficient building per year; probably one prize for the contractor and one for the consultant.

\subsection{The Arm of Legislations}

Setting proper legislation for any system will lead to better achievements meeting the objectives of such a system. The following legislation will contribute positively to accelerating BIPV and BIWT construction in Bahrain:

- Introduce a feed in tariff; similar to Germany, Spain, Japan, USA, etc.

- Impose a law that forces all commercial construction to have at least $10 \%$ of its electricity from solar or wind or combination.

- Offer a limited electrical power from conventional source for each $\mathrm{m}^{2}$ (may be $10 \mathrm{~W}$ per $\mathrm{m}^{2}$ ), i.e. limit the building's electrical requirements per $\mathrm{m}^{2}$ or index of peak energy consumption. There can be 5 different indices for houses, office buildings, public buildings, hotels and schools.

- Impose a law that oblige schools and governmental buildings to have $15 \%$ of their electricity from solar and wind energy.

- Establish national green building code This code should involve the major elements set by LEED or BREEAM. Even better, is including this code within the proposed Bahrain Green Building Council. In this code, the energy part should have a large percentage share (no less than 40\%). Hence, BIPV and BIWT will have a substantial influence. In USA a new national standard to provide minimum guidelines for green building practices has been finalized in 2008 . ASHRAE (www.ashrae.org), in conjunction with the Engineering Society of North America and the USGBC, is developing ASHRAE 189 - Standard for the design of high-performance Green Buildings, excluding low-rise residential buildings. 


\subsection{The Arm of Penalties}

Although people hate penalties, it is a punitive measure that the law imposes for the performance of an act that is proscribed, or for the failure to perform a required act. Therefore, setting legislation or laws for an energy quota or limit for a building is useful practice. Exceeding this limit, which is related to carbon emission (larger carbon footprint for a building), will lead to imposing a penalty on intruders and law breakers. For the benefit of accelerating BIPV or BIWT, which are major elements of sustainable, green and eco - buildings, one can include the following penalties:

- Penalty on buildings with high carbon print. Construction companies or investors must be fined if they made a building that has a large carbon footprint, i.e. the carbon emission resulted from direct or indirect use of energy for the building or activity. Probably, 24 ton of $\mathrm{CO}_{2}$ per year for a $400 \mathrm{~m}^{2}$ built area is considered as an optimum for Bahrain and GCC as the weather is extremely harsh and no natural greenery or water is available.

- Impose high tax on commercial investment buildings that are not using an environmentally friendly energy source like solar and wind.

- Set a limit for the ecological footprint of the country and make a penalty on investors in building construction or real states or stakeholders that highly contribute to this footprint. A 3.0 global hectares per person (7.5 ha per person) is suitable for Bahrain. The ecological footprint is a measure of human demand on the earth's ecosystems. It compares human demand with planet earth's ecological capacity to regenerate it. It represents the amount of biologically productive land and sea area needed to regenerate the resources a human population consumes and to absorb and render harmless the corresponding waste, given prevailing technology (BIPV or BIWT) and resource management practice. Using this assessment, it is possible to estimate how many planet earths it would take to support humanity if everybody lived a given lifestyle. In 2003, the average biologically productive area per person worldwide was approximately 1.8 global hectares (gha) per capita. In 2007, UK's average ecological footprint was 6.29 ha per capita. The average ecological footprint for the GCC countries was nearly 12 (UAE was 16, Kuwait was 10.3 and Saudi Arabia was 6.1 ha per capita; no data for Bahrain, Qatar and Oman), USA was 12.2 , Germany was 6.3, Japan was 5.9, India was 1.06 and Bangladesh was only 0.5 ha per capita; knowing that each gha $=2.47$ ha.

The human footprint has exceeded the incapacity (the available supply of natural resources) of the planet by $20 \%$. The available biological capacity for the 6 billion people on earth in 1992 was about 1.3 hectares per person, which is smaller than the 1.8 global hectares because it did not include bio-productive marine areas.

\subsection{The Arm of Strategies}

Civilized and cautious governments and parliaments should have clear strategies with regards to housing, building and construction sector. This sector, as we showed earlier consumes nearly $55 \%$ of the national energy produced. This energy is needed for producing, transportation, damping and recycling of building materials, as well as manpower. Water production, cooling, heating and ventilation - for thermal comfort - are important and require an energy source. Conventional sources of energy are available in the region but are polluting, i.e. each $\mathrm{kWh}$ of electricity from conventional source (natural gas) emits nearly $1 \mathrm{~kg}$ of $\mathrm{CO}_{2}$ in production. With the huge investment in construction and real state which have shown that it is a fast money making business the environment had been badly affected. Therefore, strategies should be made so that clean and renewable energy sources are available for building and construction, especially that the projected additional electricity capacity needed by 2010 in GCC countries is as follows:

- Bahrain - 1200MW at an estimated cost of US\$900 million

- Kuwait - 3400MW at an estimated cost of US\$2.5 billion

- Oman - 1100MW at an estimated cost of US $\$ 900$ million

- Qatar - 800MW at an estimated cost of US\$600 million Saudi Arabia - 20000MW at an estimated cost of US $\$ 15$ billion

- United Arab Emirates - 6600MW at an estimated cost of US $\$ 5.1$ billion

The following strategies should be considered in Bahrain in order to accelerate the BIPV and BIWT projects, either directly or indirectly:

- Establish bahrain green building council. On 30 July 2008 the Gulf Green Building Society was officially launched in Kuwait. The founders are representatives from Bahrain, Kuwait, Saudi Arabia, United Arab Emirates and Qatar. Now, there is Emirates Green Building Council, Saudi Green Building Council and Qatar Green Building Council. It is expected that Bahraini Green Building Council will be due in mid 2009; we are offering all the advice and assistance to the government and environmentalist to achieve this goal. This council will consider energy, atmosphere, site, water, and recycling, material and indoor quality. These are the major elements for sustainable building. BIPV and BIWT are incorporated in the energy part. Green Buildings are in fact eco-buildings, Eco Homes, smart buildings or sustainable buildings. According to Wikipedia, the 2006 version of Eco Homes increases the standards for energy efficiency, following the 2006 revisions energy efficiency requirements of the Building Regulations.

- Establish certification or an environmental rating for building. In UK the environmental rating scheme for homes was set by Building Research Establishment's Environmental Assessment Method (BREEAM), which can also be applied to a 
variety of nonresidential buildings. It was replaced by the Code for Sustainable Homes in April 2007.

BREEAM criteria for design and procurement include the following: Management, Health \& Wellbeing, Energy, Transport, Water, Materials, Land Use, Ecology and Pollution. USA had established LEED certification made by US Green Building Council. LEED stands for Leadership Environmental Engineering Design. LEED criteria are: Sustainable sites, Water efficiency, Energy \& Atmosphere, Material and Resources, Indoor environmental quality, Innovation and design.

Also, there is certification of CASBEE (Comprehensive Assessment System for Building Environmental Efficiency. CASBEE criteria include: Indoor Environment, Quality of Service, Outdoor Environment, Energy, Resources and Materials, Reuse and reusability, Off-site environment GB Tool is also a type of certification. Its criteria include: Energy consumption, Resource consumption, Environmental loading, Indoor Environmental Quality, Site criteria and Social and economic measures. Finally, there is Green Globes US. Its criteria includes: Project Management, Site, Energy, Water, Indoor environment, Resource, building materials and solid waste.

In all of them, the rating is made according to a weighting system where it is used later to designate the home as Pass, Good, Very good, or Excellent or awards points .

- Establishing rating or certification - based on points - will accelerate BIPV and BIWT since they count for large points. The target for this certification is making the Living Building prerequisites include net-zero annual energy production from on-site renewable, net-zero water consumption from rainwater collection and reuse, carbon offset for embodied energy in the building's construction, set-aside of land for habitat equal to the area of the project site, maximum distance materials may travel to site by weight and others.

- Encourage the Clean Development Mechanism (CDM) concept and projects. CDM will lead to own Certificates of Emission Reduction (CERs) each reduction of one ton $(1000 \mathrm{~kg})$ of $\mathrm{CO}_{2}$ qualify for CER. These certificates are initially set to have a value of USD 10 but it will end with a value USD 100 or more close to year 2012! CDM considers BIPV or BIWT as projects entitled for endorsement in CDM since they reduce emissions of $\mathrm{CO} 2$ (indirectly) especially building consumes 30 to 40 of electricity produce by the country. Nearly $1000 \mathrm{CDM}$ projects had been internationally approved and they are worth 200 million CERs. This is in fact a very small number as the required number of CERs is 2 to 3 billion by 2012 ! Unfortunately, nearly 10 projects are from the Middle East and only one project from Qatar in Gas flaring. There is one project in Bahrain (Carbon injection) which is in the process of evaluation.

- Improve the Sustainable Building Index (SBI). This is our index which has been published in the journal of Energy and Buildings. This is explained in the above section.

- Now, our SBI is only 0.48 , therefore, we have to overcome the barriers and increase the drives in BIPV and BIWT in Bahrain. SBI of more than 0.8 should be set as a target in one year.

- Consider all international environmental reports like Environmental Performance Index (set by University of Yale in collaboration with University of Colombia). The 2008 Environmental Performance Index (EPI) ranks 149 countries on 25 indicators tracked across six established policy categories: Environmental Health, Air Pollution, Water Resources, Biodiversity and Habitat, Productive Natural Resources, and Climate Change. The EPI identifies broadly-accepted targets for environmental performance and measures how close each country comes to these goals.

As a quantitative gauge of pollution control and natural resource management results, the Index provides a powerful tool for improving policymaking and shifting environmental decision making onto firmer analytic foundations. In 2008 the GCC countries were in low rank (Saudi Arabia 78, Oman 91, Kuwait 111, UAE 112 and no data for Bahrain!). UK was in rank 14, USA 39, while Switzerland was rank 1.

Also following International reports on carbon footprint on a periodical basis is important and will lead to the acceleration of BIPV and BIWT. The carbon footprint is a measure of the exclusive global amount of carbon dioxide $\left(\mathrm{CO}_{2}\right)$ and other greenhouse gases emitted by human activity or accumulated over the full life cycle of a product or service. Normally, a carbon footprint is expressed as a $\mathrm{CO}_{2}$ equivalent (usually in kilograms or tonnes), which accounts for the same global warming effects of different greenhouse gases. Unfortunately, Bahrain is among top 10 countries with high carbon footprint (23.9 ton of $\mathrm{CO}_{2}$ per capita). The typical figure is no more than 2 ton of $\mathrm{CO}_{2}$ per capita (Table 1).

- Improve the electrical system integration between the national grid and electricity from PV or wind electricity produced from buildings, i.e. BIPV or BIWT, or other means of renewable energy. The national grid should be capable to receive the feed - in electricity from BIPV or BIWT without disturbance. Also, a good metering system must be made available so that the end user (customer) and the producer (Authority of Electricity and Water, AEW, or Utility private companies) is able to read the feed in electricity from BIPV or BIWT to the national grid and the consumed electricity from the AEW in order to determine the reduction in $\mathrm{CO}_{2}$ emission and consequently offer a bonus for each clean $\mathrm{kWh}$ produced. This will eliminate and alleviate the use of Batteries in the BIPV and BIWT.

Net metering service is a service to an electric consumer under which electric energy generated by that electric consumer from an eligible on-site generating facility and delivered to the local distribution facilities may be used to offset 
Table 1. Ranks of Carbon Footprint of Different Countries from 1990 to 2004. http://en.wikipedia.org/wiki/List_of_countries_by_carbon_dioxide_emissions_per_capita

\begin{tabular}{|c|c|c|c|c|c|c|c|c|c|c|c|c|c|c|c|c|}
\hline Rank & Country & 1990 & 1991 & 1992 & 1993 & 1994 & 1995 & 1996 & 1997 & 1998 & 1999 & 2000 & 2001 & 2002 & 2003 & 2004 \\
\hline 1 & Qatar & 22.5 & 37.4 & 55.3 & 62.1 & 60.2 & 60.4 & 61.4 & 68.7 & 60.3 & 56.9 & 60.1 & 66.3 & 67.4 & 63.1 & 69.2 \\
\hline 2 & Kuwait & 21.1 & 5.5 & 10.0 & 16.4 & 20.6 & 32.3 & 28.4 & 28.1 & 33.8 & 32.6 & 31.7 & 28.8 & 27.1 & 31.1 & 38.0 \\
\hline 3 & U A E & 29.3 & 30.2 & 29.4 & 31.0 & 33.0 & 30.2 & 16.9 & 17.7 & 36.4 & 36.0 & 35.6 & 33.5 & 33.7 & 33.6 & 37.8 \\
\hline 7 & Bahrain & 22.5 & 21.9 & 19.5 & 27.2 & 26.6 & 27.2 & 25.9 & 27.9 & 28.8 & 27.4 & 27.8 & 26.4 & 30.6 & 31.0 & 23.9 \\
\hline 10 & U S A & 18.9 & 18.7 & 18.4 & 19.3 & 19.5 & 19.3 & 19.4 & 20.2 & 19.8 & 19.9 & 20.4 & 20.1 & 20.0 & 19.8 & 20.4 \\
\hline
\end{tabular}

electric energy provided by the electric utility to the electric consumer during the applicable billing period.

Net metering is an electricity policy for consumers who own, generally small, renewable energy facilities, such as wind or solar power. "Net", in this context, is used in the sense of meaning "what remains after deductions". In this case, the deduction of any energy outflows from metered energy in flows. Under net metering, a system owner receives retail credit for at least a portion of the electricity they generate. The ideal is to make the customers existing electricity meter spin backwards, effectively banking excess electricity production for future credit. In reality, the rules vary significantly by country.

The Authority of Electricity and Water, AEW, or any electric utility shall make available, upon request, net metering services to any electric consumer that the electric utility serves.

New Jersey and Colorado are widely considered to have the best net-metering policies in the United States as both have no limit on enrollment (less than 2MW each), roll over month to month and pay annually for excess generation at an avoided-cost rate (New Jersey) or incremental cost (Colorado) .

In making the net metering the government can establish Feed-in-Tariff, making use of different worldwide experience. Table 2 shows different incentive rates for solar electricity from BIPV or BIWT [21].

The United Kingdom government is reluctant to introduce the net metering principle because of complications in paying and refunding the value added tax that is payable on electricity, but pilot projects are underway in some areas.

In fact, investors do not like to incorporate batteries in BIPV due to its negative environmental impact as well as its cost and maintenance. Sharp company [22] made a case study for installing $100 \mathrm{~kW}$ thin PV and compared it with Silicon polycrystalline PV. They preferred thin films due to the following reasons:

- Less use of silicon material, no material shortage problem (Resource Saving).

Table 2. Typical Feed-In Tariffs in USD [21]

\begin{tabular}{|c|c|c|c|c|}
\hline & Wind & Photovoltaics & Hydro & Biomass \\
\hline Austria & 0.101 & 0.615 & & 0.227 \\
\hline California & & 0.500 & & \\
\hline Czech Republic & 0.115 & 0.620 & & \\
\hline Germany & 0.105 & 0.658 & 0.100 & 0.147 \\
\hline Italy & & 0.595 & & \\
\hline Minnesota & 0.048 & & & \\
\hline Spain $<50 \mathrm{MW}$ & 0.078 & 0.451 & 0.078 & 0.078 \\
\hline Turkey & 0.067 & & & \\
\hline Washington State & & 0.620 & & \\
\hline
\end{tabular}


- Superior temperature-characteristics to crystaltype Si solar module.

- $50 \%$ up in power from amorphous type - mainstream of thin film solar module.

- Improved-strength design adopting tempered glass for cover glass.

- Versatile applications such as BIPV and See Thru Thin Film PV.

- Improved appearance.

Thin films PV's, as a general rule of thumb, need roughly double the amount of area of modules for the same $\mathrm{kW}$ output due to their lower efficiency, however, they operate on a larger solar spectrum [23]. Sharp [22] installed in their test 1200 solar PV modules, each of efficiency $8 \%$ and weighing $18 \mathrm{~kg}$ rated as $85 \mathrm{~W}$ thin film (NA $851 \mathrm{WQ}$ ). The required area was $1283 \mathrm{~m}^{2}$. They found that for each $\mathrm{kW}$ PV of this type the power out is $1527 \mathrm{kWh} / \mathrm{y}$ (while for crystalline PV it is $1434 \mathrm{kWh} / \mathrm{y}$ ). This is good harnessing from the sun since, theoretically, the average solar irradiation in Bahrain is $60.8 \mathrm{kWh} / \mathrm{m}^{2}$ on surface titled at angle of surface of $25^{\circ}$ (Bahrain latitude is $26^{\circ} \mathrm{N}$ ) - this is the best tilt angle for PV installation in Bahrain, according to their study. They found that the PV electricity for installing $100 \mathrm{~kW}$ at tilt of $25^{\circ}$ is $143371 \mathrm{kWh} / \mathrm{y}$ using polycrystalline PV, while for thin films it is $152660 \mathrm{kWh} / \mathrm{y}$ (Table 3).

In Japan the yield will be less than Bahrain by $28 \%$, while India is larger than Bahrain by $21 \%$. (This is due to the effect of heat (temperature) on PV; Average temperature in Bahrain is $26.5^{\circ} \mathrm{C}$ while in Japan is $15.6^{\circ} \mathrm{C}$ ). This means for $100 \mathrm{~kW}$ PV thin film the saved $\mathrm{CO}_{2}$ is $105515 \mathrm{~kg}$ (106 ton) and is $99000 \mathrm{~kg}$ (99 ton) for crystalline silicon, annually. If batteries are needed to store $100 \mathrm{~kW}$ at $10 \mathrm{hrs}$ at night (1000 $000 \mathrm{Wh}$ ) with $12 \mathrm{~V}$ and $200 \mathrm{Ah}$ batteries, then we need:

Number of batteries $=$ Energy needed $/(200 \mathrm{Ah} \times 12 \mathrm{~V})$ $=1000000 \mathrm{Wh} /(2400)=417$.

This is a large number of batteries. It can be reduced if one wants only 6 hours at night; which become 250 . This large number of batteries is a burden on investors as each battery costs nearly USD200.

\section{Adopt the Word Bank Study for Bahrain: Local Manufac-} turing of RE Technologies

The World Bank conducted a study for the Ministry of Finance at the kingdom of Bahrain for the purpose of investing in renewable energy. We made a significant contribution (see the appendix). The objective of the study is to devise a strategy for developing and using alternative energy in Bahrain as an integrated component of energy supply and to examine the economic and business opportunities for Bahrain to supply alternative energy technologies and services for its own use and to other countries in the region. Renewable energy resources should have a strong contribution in the energy option in Bahrain as the country's gas reserve is declining (Fig. 1).

Declination of natural gas will affect demand and supply. In 2018 it is expected that demand will be more than supply (Fig 2). Therefore, reducing energy for the building and construction sector is important. BIPV and BIWT play an im- portant role and consequently the prices of natural gas will increase substantially (Table 4).

Table 4 indicates, that the present cost structure (generation capital cost, operation and maintenance, fuel cost,...etc) will be double in 2015 compared to 2005. The total cost of natural gas in 2005 is $3.3 \phi / \mathrm{kWh}$ and will jump to $6.29 \phi /$ $\mathrm{kWh}$ for gas based and $9.02 \varnothing / \mathrm{kWh}$ to oil based. According to the study the Renewable Energy Options for Bahrain are:

\section{Wind Power}

- Stand-alone wind power

- On-shore utility-scale wind farms

- Off-shore utility-scale wind farms

\section{Solar Energy}

- Solar water heaters

- Solar cooling systems

- Solar PV

- Large-scale concentrating solar power (CSP)

- Biomass energy is not a major source for Bahrain except municipal solid waste and sewage. Also, there is no significant hydroelectric energy as well as tidal energy. Wave energy is too far off in future. The study of the World Bank came up with the following advantages if the government is engaged in the Local Manufacturing of RE Technologies:

\section{Economic Benefit Could be Significant}

- Every country has Renewable Energy (RE) on its agenda. Therefore, Bahrain should have it.

- Economic incentive has never been this high from RE.

- Political profile and international pressure are pushing GCC countries towards RE.

\section{Employment (Job Creation) is Significant}

- Manufacturing of the equipment.

- Construction and installation of projects.

- Operation and maintenance of the projects over their lifetime. (Note that Denmark employs 20,000 in the wind industry)

\section{Bottlenecks (Barriers) are also Significant}

- Competition from big players.

- Competition from emerging players.

- Stable and sizeable domestic demand.

- Complementarily with local industry and services.

- Business environment.

- Financial "muscle".

\section{Business Models}

- Based on R\&D initiated by a domestic firm or in combination with other domestic research entities. 
Table 3. Comparison Between Power Output of $1 \mathrm{~kW}$ of Thin Film PV (Top) and 1 kW Crystalline Silicon PV (Bottom) Having Similar Area, in Bahrain [22]

\begin{tabular}{|c|c|c|c|c|c|c|c|c|}
\hline Month & & & & Inclination & & & & \\
\hline & $0^{\circ}$ & $5^{\circ}$ & $10^{\circ}$ & $15^{\circ}$ & $20^{\circ}$ & $25^{\circ}$ & $30^{\circ}$ & $35^{\circ}$ \\
\hline Jan & 89 & 96 & 102 & 109 & 113 & 118 & 121 & 124 \\
\hline Feb & 103 & 109 & 115 & 119 & 123 & 127 & 129 & 131 \\
\hline Mar & 115 & 118 & 121 & 123 & 124 & 125 & 125 & 125 \\
\hline Apr & 134 & 134 & 136 & 136 & 135 & 134 & 132 & 129 \\
\hline May & 142 & 142 & 141 & 139 & 137 & 134 & 130 & 126 \\
\hline Jun & 147 & 146 & 144 & 142 & 138 & 134 & 130 & 124 \\
\hline Jul & 137 & 136 & 135 & 133 & 131 & 127 & 123 & 118 \\
\hline Aug & 132 & 133 & 134 & 133 & 132 & 131 & 128 & 125 \\
\hline Sep & 125 & 128 & 130 & 132 & 133 & 133 & 132 & 131 \\
\hline Oct & 110 & 115 & 120 & 124 & 127 & 130 & 131 & 132 \\
\hline Nov & 96 & 104 & 111 & 116 & 122 & 126 & 131 & 133 \\
\hline Dec & 82 & 88 & 94 & 100 & 104 & 109 & 112 & 115 \\
\hline Total & 1410 & 1449 & 1482 & 1505 & 1520 & 1527 & 1525 & 1513 \\
\hline Ratio $20^{\circ}$ & $92.39 \%$ & $94.90 \%$ & $97.09 \%$ & $98.59 \%$ & $99.57 \%$ & $100 \%$ & $99.87 \%$ & $99.12 \%$ \\
\hline
\end{tabular}

\begin{tabular}{|c|c|c|c|c|c|c|c|c|}
\hline Month & & & & Inclination & & & & \\
\hline & $0^{\circ}$ & $5^{\circ}$ & $10^{\circ}$ & $15^{\circ}$ & $20^{\circ}$ & $25^{\circ}$ & $30^{\circ}$ & $35^{\circ}$ \\
\hline Jan & 86 & 92 & 99 & 104 & 109 & 113 & 117 & 120 \\
\hline Feb & 99 & 105 & 111 & 115 & 119 & 122 & 125 & 126 \\
\hline Mar & 110 & 113 & 115 & 117 & 118 & 119 & 119 & 119 \\
\hline Apr & 126 & 127 & 128 & 128 & 128 & 126 & 125 & 121 \\
\hline May & 132 & 132 & 131 & 130 & 127 & 124 & 121 & 117 \\
\hline Jun & 135 & 135 & 133 & 131 & 128 & 124 & 119 & 114 \\
\hline Jul & 126 & 125 & 124 & 122 & 120 & 117 & 113 & 109 \\
\hline Aug & 122 & 122 & 123 & 122 & 122 & 120 & 118 & 115 \\
\hline Sep & 115 & 118 & 120 & 122 & 123 & 123 & 122 & 121 \\
\hline Oct & 103 & 107 & 112 & 116 & 119 & 121 & 122 & 123 \\
\hline Nov & 91 & 98 & 105 & 110 & 115 & 120 & 124 & 126 \\
\hline Dec & 78 & 85 & 91 & 95 & 100 & 104 & 108 & 111 \\
\hline Total & 1323 & 1360 & 1392 & 1413 & 1427 & 1434 & 1432 & 1422 \\
\hline Ratio $20^{\circ}$ & $92.29 \%$ & $94.86 \%$ & $97.07 \%$ & $98.54 \%$ & $99.55 \%$ & $100 \%$ & $99.90 \%$ & $99.19 \%$ \\
\hline
\end{tabular}




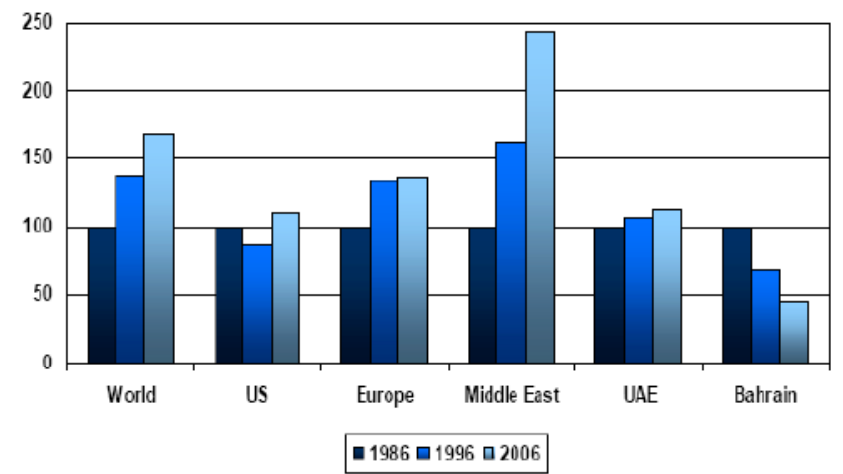

Fig. (1). The gas reserve declination in Bahrain and other countries [21].

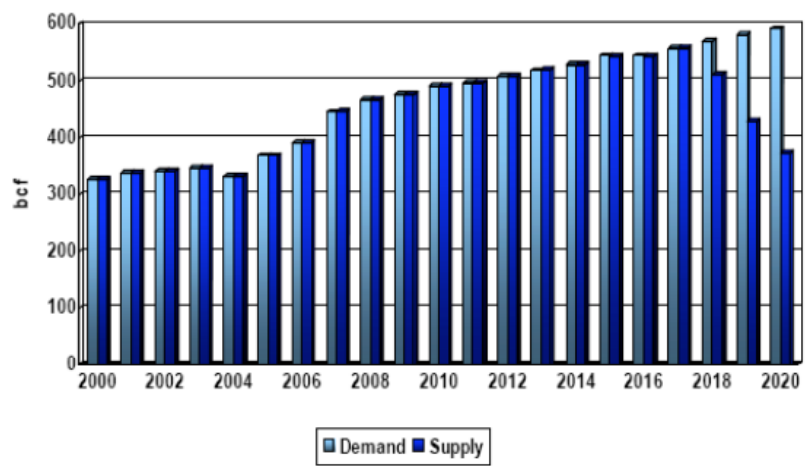

Fig. (2). The Bahrain gas and supply scenario [21].

- A leading international manufacturer establishing a local presence in which certain components or entire systems are manufactured in the local market.

- A licensing agreement based on which a domestic firm acquires the technology and may further innovate/adapt the technology prior to manufacturing.

- Joint venture between a leading manufacturer and a local firm.

Table 5 summarizes, the government's policy to support local manufacturing of RE technologies in different countries in Wind Turbine Manufacturing [21]- as an example. The study made a Strategic approach toward local manufacturing of RE technologies. These are:

- Be aggressive with implementation of RE in Bahrain but claim GCC as your local market.

- Conduct high profile demonstrations of technologies especially relevant to region.

- Become known for carrying out long term adaptive R\&D on a select number of technologies.

- Partnership with leading international manufacturers.

- Make the kingdom of Bahrain a favorable location for the installation of new manufacturing plants for key technologies.

\section{On Short- to Medium-term Agenda}

* Become a showcase in GCC for:
Table 4. Comparison of the Gas Cost Structure in 2005 to that in 2015 [21]

\begin{tabular}{|c|c|c|}
\hline \multicolumn{3}{|c|}{ Present Cost Structure (2005) } \\
\hline & Fils/kWh & $\phi / \mathrm{kWh}$ \\
\hline Generation capital cost & 2.2 & 0.59 \\
\hline O\&M cost & 1.1 & 0.29 \\
\hline Fuel cost & 4.3 & 1.14 \\
\hline Total generation & 7.6 & 2.02 \\
\hline T\&D & 5.01 & 1.33 \\
\hline Total cost & 12.6 & 3.35 \\
\hline Forecast Cost Structure (2015) & Oil-based \\
\hline Generation capital cost & Gas-based & 1.82 \\
\hline O\&M cost & 1.32 & 0.91 \\
\hline Fuel cost & 0.52 & 4.97 \\
\hline Total generation & 2.95 & 7.52 \\
\hline T\&D & 4.79 & 1.5 \\
\hline Total cost & 1.50 & 9.02 \\
\hline
\end{tabular}

- Solar water heaters in the commercial and industrial sectors.

- Geothermal exchange cooling systems.

- Seawater district cooling.

- Efficient air-conditioning systems.

* Become a partner in adaptive R\&D with some wellknown entities (manufacturers and research organizations) in:

- Manufacturing of various cooling systems.

- Modular AC/DC air conditioning systems.

- Wind power technologies.

- Solar thermal power.

- Launch a program of high quality wind measurements at several potential sites including some off-shore oil platforms.

* Become an exporter of solar-grade silicon. This requires a large technical survey on the desert terrain of Bahrain.

\section{On Medium- to Long-term Agenda}

*Become a showcase in GCC for:

- Wind farms.

- Solar air conditioning.

- Rooftop PV and net metering.

- Solar thermal power. 
Table 5. Some Government Policies to Support Manufacturing RE Technologies [21]

\begin{tabular}{|c|c|c|}
\hline Policy & Purpose & Countries \\
\hline \hline 1- Local content requirement & $\begin{array}{c}\text { Encourages leading manufacturers to transfer technology. } \\
\text { Should be applied in a gradual and staged manner. }\end{array}$ & Spain, China, Brazil, Canada. \\
\hline 2- Financial and tax incentives & Improves financial viability through low-interest loans, tax credits, and \\
direct investment in joint ventures. & $\begin{array}{c}\text { Denmark, Germany, Spain, } \\
\text { China. }\end{array}$ \\
\hline $\begin{array}{c}\text { 3- Indirect financial support through } \\
\text { market creation }\end{array}$ & $\begin{array}{c}\text { Improves economic viability through the increased volume, feed-in tariffs, } \\
\text { mandatory energy targets, government tendering, financial and tax incen- } \\
\text { tive for development and use of RE. }\end{array}$ & $\begin{array}{c}\text { Germany. Denmark, Spain, } \\
\text { India, China, UK, US. }\end{array}$ \\
\hline
\end{tabular}

- Become a supplier of equipment and services; candidate technologies include:

- Manufacturing of wind systems.

- Manufacturing of efficient air conditioning, solar cooling systems.

- Manufacturing of solar PV.

- Manufacturing of solar thermal systems.

Some important notes had been made in the study on promising medium term technologies. These are:

- Absorption coolers. Proven non-electric A/C technology; they are the first step for future full solar cooling systems. They have high potential for GCC countries. However, they need natural gas connection. Bahrain should first study the viability of establishing an urban gas distribution system.

- Emerging modular AC/DC air-conditioning systems ("Solcool"). It is of high potential for the GCC countries since it is more efficient electric A/C. They operate on PV. However, they are of high cost and still of unknown performance. Bahrain could partner with international players for adaptive $\mathrm{R} \& \mathrm{D}$.

○ Wind power. It is quite attractive, especially onland systems. It needs multi-year wind speed measurements for large-scale grid-connected investments. This power should be made part of the medium-term strategy.

- Roof-top PV and net-metering. EU and the United States encourage this practice aggressively. It is conceptually attractive to GCC, but its costs are too high at this stage.

- Solar thermal power. It is expected to be the most cost efficient technology. It is expected to reach 5000 MW by 2015 . Bahrain should stay on the top of developments in this area.

The innovation of BIPV is becoming wide. It is worth noting that manufacturing PV using various technologies Crystalline Silicon (Mono and Poly), Thin films (Silicon), Thin compounds, Organic PV) - is a wise decision to be taken into consideration by the government. The survey made by Marsh [23] is worth considering. It illustrates several success stories and applications with a highlight on cost. According to Marsh, SolarSave roofing tiles from Open Energy Corporation are solar PV/polycarbonate tiles which are manufactured in black, red/brown and blur/gray colours. Each tile weighs $12 \mathrm{lb}$ (nearly $3 \mathrm{~kg}$ ), measures 17 in by 36 in and provides up to $35 \mathrm{~W}\left(87 \mathrm{~W} / \mathrm{m}^{2}\right) 48 \mathrm{VDC}$. Locally manufacturing such a product as a joint venture is a promising commercial business with positive refection on BIPV dissemination. United Solar Ovonic, LLC makes UniSolar BIPV material. Partner companies of UniSolar are ThyssenKrupp, Alwitra, Corus and Solar Integrated Technologies. The American Energy Technologies Inc has installed over 5000 peel and stick UniSolar panels on a metal roof of a large warehouse to generate up to $700 \mathrm{~kW}$. Sun Edison LLC is using them over $74000 \mathrm{ft}^{2}$ of metal roof of a large distribution centre in Connecticut to provide up to $433 \mathrm{~kW}$ of power. Schott successfully deposited amorphous silicon semiconductor material onto glass in a layer less than a micron thick, whereas wafers of crystalline silicon are at least 180 microns thick. Solar Solutions LLC produces PV material embedded in glass and allows $10 \%$ of natural light through when generating full power (see thru). First Solar Inc has produced a high rate vapor transport deposition process for depositing cadmium telluride based semi-conductors ( thin film compound) onto glass substrate pane by pane and quotes a price USD 1.87 / W compared with crystalline silicon cells at around USD 2 /W to USD $3 / \mathrm{W}$. After awarding Nobel Prize to Alan Heeger in 2000, for his work on Organic PV (OPV), followed by another Nobel Prize to Alan MacDiarmid and Hideki Shirakawa (Americans) with a Korean Kwanghee Lee organic solar cells are expected to have an efficiency of $25 \%$.

Masdar, the clean energy arm of the government of Abu Dhabi, just announced that it will invest USD2 billion in tin film [24]. Nanosolar announced that they achieve radical cost savings by directly applying photo-active chemicals with ink composed of nano particles. They are producing Nanosolar's Power Sheet cells which roll off the machines like pages of newspaper in a printing press at a rate of several hundred feet a minute. They claim that starting from December 2008 they will sell thin films panels at USD1 per $\mathrm{W}$ ! The Bahrain government should think seriously about becoming partners with such leading companies in PV manufacturing in BIPV. 


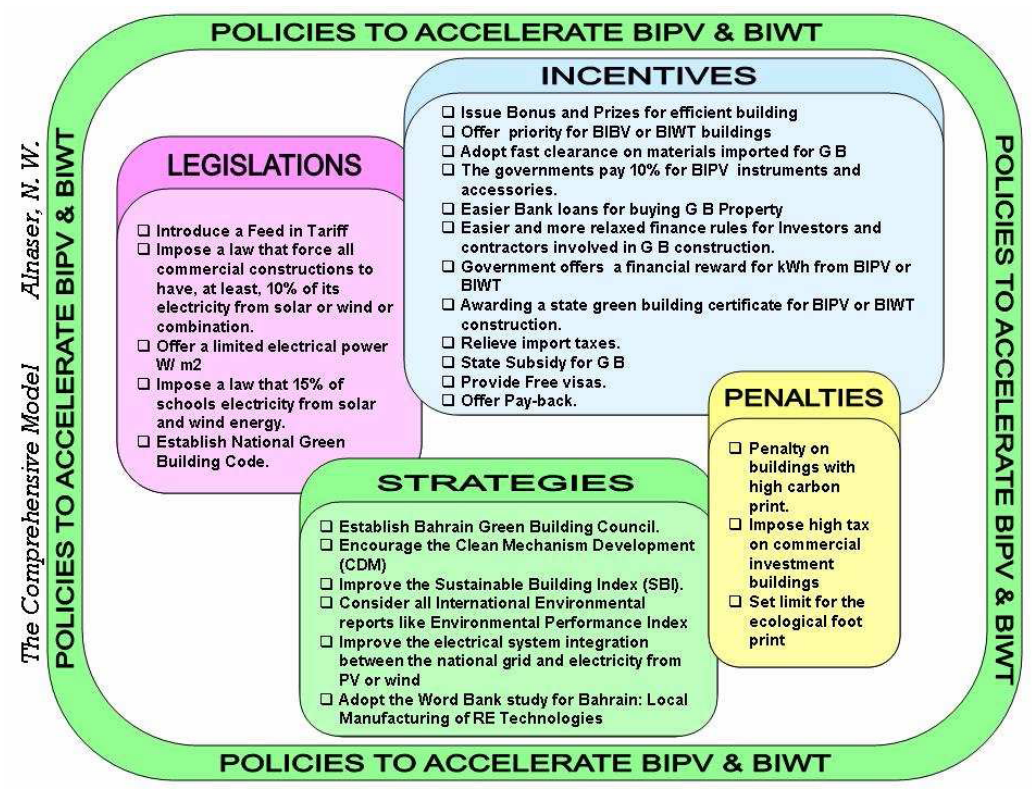

Fig. (3). Summary of the comprehensive model.

\section{CONCLUSION}

Our "comprehensive" model relates our mathematical model [18], which allows the calculation of the sustainable building index (SBI), with policies that the government of Bahrain should initiate and undertake in order to accelerate the BIPV and BIWT building projects in Bahrain. These policies are of many arms: incentives, legislations, penalties and strategies. Any operation in any of the arms will lead to a diffusion of BIPV and BIWT projects and hence a reduction of $\mathrm{CO}_{2}$ emission in Bahrain. Furthermore, it will prolong depleted energy resources and utilize them for other industrial processes (petrochemicals). This will increase Bahrain's Environmental Performance Index and the Ecological footprint as well as reduce the Carbon footprint. Fig. (3) summarizes the comprehensive model. This model will be a working agenda for parliament and the government of the kingdom of Bahrain as its major content is indorsed in the report made by the World Bank [21] to the government of Bahrain.

\section{REFERENCES}

[1] N. Lior, "Future power generation and role of renewable energy", Oil and Arab Cooperation, vol. 33, Issue 121, pp. 145-179, 2007

[2] A. Al Karaghouli, "Current states of renewable energies in the middle east-north african region", UNEP/ROWA 2007, Special report, Manama, Kingdom of Bahrain (obtained by a request to uneprowa@unep.org.bh), 2007.

[3] Organization of Arab Petroleum Exporting Countries-OAPEC, General Secretary Report, Kuwait, 104-112 (www.oapecorg.org), 2007.

[4] A. Sayigh, "Worldwide progress in renewable energy", ISESCO Science and Technology Vision, vol.3, number 4, pp. 86-90, 2008.

[5] W.E. Alnaser, and N.W. Alnaser, "Solar and wind energy: excellent options for the energy mix in the GCC countries", In Proceedings of the ECSSR 13th Annual Energy Conference entitled Future Arabian Gulf Energy Sources: Hydrocarbon, Nuclear or Renewable? Emirate Centre for Strategic Studies (ECSSR), Abu Dhabi, 19-21 November 2007, (in Press).

[6] K.D. Patlitzianas, H. Doukas, A.G. Kagiannas, and J. Psarras, "Sustainable energy policy indicators: review and recommendations", Renewable Energy, vol. 33, Issue 5, pp. 966-973, 2008.
[7] K.D. Patlitzianas, H. Doukas, A.G. Kagiannas, and J. Psarras, "Enhancing renewable energy in the arab states of the gulf: constraints \& efforts", Energy Policy, vol. 34, Issue 18, pp. 3719-3726, 2006.

[8] P. Metsis Th., "Sustainable Building Design for Bahrain Sustainable Building Design Expo 2008, June 16-18, Bahrain International Exhibition Centre, Kingdom of Bahrain, 2008 (CD Proceeding can be obtained from the Bahrain Society of Engineering).

[9] A.Y. Abdalla, "Application of Energy Efficiency, and Renewable Energy in Bahraini Buildings Expo 2008", CD Proceeding can be obtained from the Bahrain Society of Engineering. June 16-18, Bahrain International Exhibition Centre, Kingdom of Bahrain, 2008.

[10] W.E. Alnaser, R. Flanagan, S. El-Masri, S.E. Al- Khalifa, S.D. Probert, and N.W. Alnaser, "Bahrain's formula 1 racing circuit: energy and environmental considerations", Applied Energy, vol. 83, pp. 352-370, 2006.

[11] N.W. Alnaser, R. Flanagan, S.E. Al-Khalifa, R. "Construction and environmental matters of bahrain's international formula1 circuit"; Mumtaz, S. El-Masri and W.E. Alnaser, "Architectural", Building and Environment, vol. 42, pp. 495-506, 2006

[12] N.W. Alnaser and R. Flanagan, "The need of sustainable buildings construction in the kingdom of bahrain", Building and Environment, vol. 12, Issue 1, pp. 1783-1791, 2007.

[13] W.E. Alnaser, and N.W. Alnaser, "The Solar Connection of the Muslim Community", ISESCO Journal of Science and Technology, 2008 (in press).

[14] N.W. Alnaser, "Building integrated photovoltaic for thermal comfort in bahraini buildings", Journal of Arab Association Universities for Basic and Applied Sciences, vol. 4 (Suppl), pp. 147-156, 2006.

[15] W.E. Alnaser, H. Timme, H. Al Buflasa, and N.W. Alnaser, "Wind characteristics and wind power analysis in bahrain for building integrated wind turbine applications and $\mathrm{CO}_{2}$ emission reduction", Journal of Arab Association Universities for Basic and Applied Sciences, vol. 4, pp. 298-306, 2008.

[16] N.W. Alnaser, R. Flanagan, and W.E. Alnaser, "Potential of making - over to sustainable buildings in the kingdom of bahrain", Energy and Buildings, vol. 40, pp. 1304-1323, 2008.

[17] N.W.Alnaser, "Towards sustainable buildings in bahrain, kuwait and united arab emirates", The Open Construction and Building Technology Journal, vol. 2, pp. 7-21, 2008.

[18] N.W.Alnaser, F. Flanagan, and W.E. Alnaser, "Model for c.calculating the sustainable building index (SBI) in the kingdom of bahrain", Energy and Buildings, vol. 40, pp. 2037-2043, 2008. 
[19] H.M. Taleb, and A.C. Pitts, "The potential to exploit use of building-integrated photovoltaics in countries of the gulf cooperation council”, Renewable Energy, vol. 34, pp. 1092-1099, 2009.

[20] k. Sopian, A.H. Haris, D. Rouss, and M.A. Yusof, "Building integrated photovoltaic (BIPV) in malaysia-potential, current status strategies for long term cost reduction", Journal of ISESCO Science and Technology Vision, vol. 1, pp. 40-44, 2005.

[21] H. Razawi "Development of alternative: energy technologies and services in the kingdom of bahrain", Presentation to the Minister of
Finance, Kingdom of Bahrain; 2007 (Presentation can be obtained from the author on hrazavi@worldbank.org).

[22] T. Isogai, "Thin film PV-the most eco-conscious alternative energy conservation”, Expo 2008, June 16-18, Bahrain International Exhibition Centre, Kingdom of Bahrain, 2008 (CD Proceeding can be obtained from the Bahrain Society of Engineering).

[23] G. Marsh, "BIPV: innovation puts spotlights on solar", Renewable Energy Focus, May/June, pp. 62-67, 2008.

[24] B. Walsh, "Solar power's new style", Time, June 23, pp. 38-39, 2008.

Received: December 05, 2008

(C) Alnaser et al.; Licensee Bentham Open.

This is an open access article licensed under the terms of the Creative Commons Attribution Non-Commercial License (http://creativecommons.org/licenses/by-nc/3.0/) which permits unrestricted, non-commercial use, distribution and reproduction in any medium, provided the work is properly cited. 